\title{
A NUMERICAL CALCIUM TRANSIENT PATTERN EQUATION IN MEDAKA EGG SURFACE
}

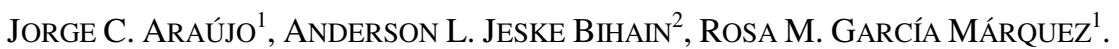

1. Departamento de Matemática, FFP, Universidade do Estado do Rio de Janeiro. 24435-005 São

Gonçalo, RJ, BRASIL.

Endereço para Correspondência

E-mails: jcaraujo_55@yahoo.com.br; rosagm@uerj.br

\section{Instituto Politécnico, Universidade do Estado do Rio de Janeiro. 28630-050, Nova Friburgo, BRASIL.}

E-mail: andersonbihaineyahoo.com.br

\begin{abstract}
We presented a numerical simulation based in the equation for diffusion with the chemical reaction with a simpler cubic kinetics to describe a simplifying transient concentration pattern of $\mathrm{Ca}^{2+}$ in the cortex upon fertilization in medaka egg fish. A uniform model with a fixed diffusion parameter and a slowly varying diffusion were compared. The concentration of $\mathrm{Ca}^{2+}$ pattern in the cortex in Medaka egg pattern was highest in the animal pole and tapering off towards the vegetal pole in agreement with the gradient of the reactivity pattern along the egg and probably reflects the gradient in $\mathrm{Ca}^{2+}$ sequestering sites of the cortical endoplasmatic reticulum membranous. Our results of the numerical simulations seem to suggest (not a proof) that must there was a stronger resequestration capacity of free calcium more than the passive diffusing into the interior of the medaka egg fish particularly near the animal pole.
\end{abstract}

Keywords— CSCR mechanism, Transient calcium pattern, Gompertz model, Biomechanical system.

\begin{abstract}
Resumo - Apresentamos uma simulação numérica baseada na equação de difusão com a reacção química com uma simples equação cinética cúbica para descrever de forma simplificada a concentração transiente de $\mathrm{Ca}^{2+}$ no córtex após a fertilização do ovo do peixe medaka. Um modelo uniforme com um parâmetro de difusão constante e uma difusão de variação lenta são comparados. A concentração de $\mathrm{Ca}^{2+}$ padrão no córtex do ovo do medaka foi maior no pólo animal e indo em direcção ao pólo vegetal de acordo com o gradiente de reatividade padrão ao longo do ovo e, provavelmente, reflecte o gradiente de $\mathrm{Ca}^{2+}$ requisitado do retículo endoplasmático membranoso. Os resultados das simulações numéricas parecem sugerir (não é uma prova) que deve haver uma forte capacidade de resequestro do cálcio livre do que o processo de difussão para o interior do ovo medaka peixe particularmente perto do pólo animal.
\end{abstract}

Palavras-chave—Mecanismo CSCR, Padrão de cálcio transiente, Modelo de Gompertz, Sistema biomecânico.

\section{Introdução}

Using the luminescence of aqueorin technique (Shimonura and Johnson, 1976), Gilkey et al. (1978, fig.1) succeeded in recording by the first once the explosive wave of $\mathrm{Ca}^{2+}$ that was initiated at the site of sperm entry and propagated along the cortex to the antipode site of the fish Medaka egg. Cheer et al(1987) adopted a model for calcium wavefronts propagation sustained by the calcium release. They shall assume that the release of calcium from internal sources as the membranous sequestering sites, (presumably cortical endoplasmatic reticulum, CER) other than the large cortical vesicles involves a calciumstimulated-calcium-release mechanism (CSCR). The Fig.1 describes certain aspects of unfertilized Medaka+ egg obtained from the experimental data of Gilkey et al.(1978). Lionel Jaffe (2006-2008) also reported that the calcium waves in the cortex of Medaka eggs are propagated by cycles of CSCR mechanism.

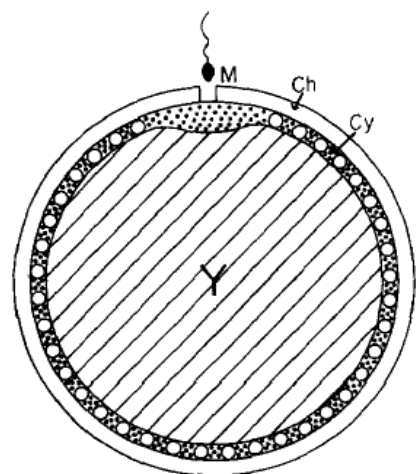

Figure 1. Diagram of unfertilized medaka egg (Gilkey et al.1978). A sperm will cross the chorion (Ch) via the mycropole (M), enter the cytoplasm (Cy) and initiate a wave of cortical vesicle secretion. Vesicles are indicated by small circles. Large central yolk (Y) compartment.

In Fig.2 (Gilkey et al. 1978, fig.2a) can be seen the free calcium wave propagation across a spermactivated medaka egg. Successive photographs are 10 s apart. The last frame is a tracing showing the leading edges of the eleven frames wave fronts. 

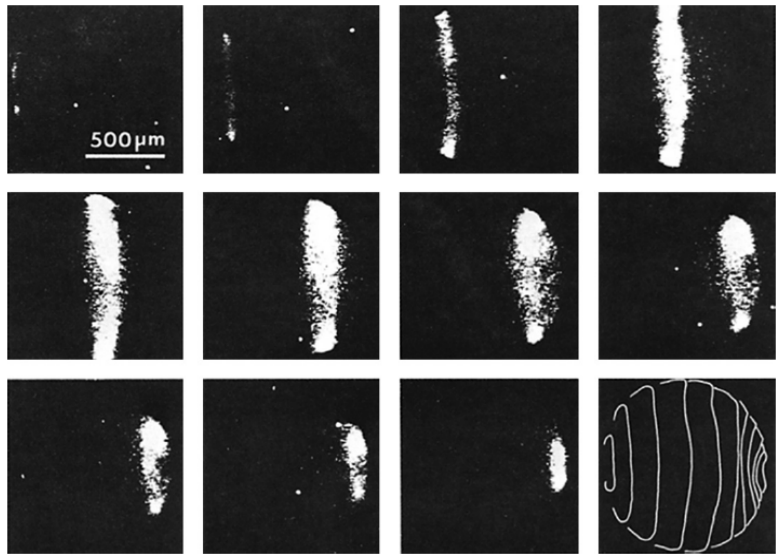

Figure 2. The calcium wave in medaka. The data showing the progression of the calcium wavefronts as it passes over the surface of the egg, beginning at the animal pole (AP). Note that the wave slows down in the vegetal hemisphere (six frames after the equator), which indicates that the cortex is not a uniform medium. AP= animal pole, $\mathrm{VP}=$ vegetal pole.

The results obtained by Gilkey et al. (1978) were generally confirmed those reported by Yoshimoto et al.(1986) that in detailed analysis of the characteristics of the aequorin luminescence technique in medaka eggs suggested that, the peak $\mathrm{Ca}^{2+}$ concentration was maintained constant during the propagation of the wave of the surface of the egg although the peak $\mathrm{Ca}^{2+}$ concentration in the cortex was higher at the animal pole. These results seem for us suspect because two reasons: (a) as reported by Yoshimoto et al.(1986) is difficult to precisely compare peak values of the $\mathrm{Ca}^{2+}$ concentration among different regions of the cortex using the luminescence of aequorin technique. In spite of these difficulties the authors related, it is obvious that the $\mathrm{Ca}^{2+}$ peak in the region of the cortex near the site of sperm entry was larger than the peak in other regions, although the difference was variable in different eggs and (b) Cheer et al, 1987(Fig.3) obtained a map of cortical reactivity in medaka eggs which indicated a gradient of reactivity along the egg: highest in animal hemisphere and tapering off towards the vegetal hemisphere. So to studies the $\mathrm{Ca}^{2+}$ concentration pattern in different latitudes of the surface of the medaka egg we take the simpler model presented by Murray (1989) to describe the CSCR mechanism. Numerical simulations were used to suggest that phase sperm- induced or artificial-induced calcium transient over the egg surface were in agreement with the reactivity cortical map pattern proposed by Cheer et al.(1987, fig.5b).

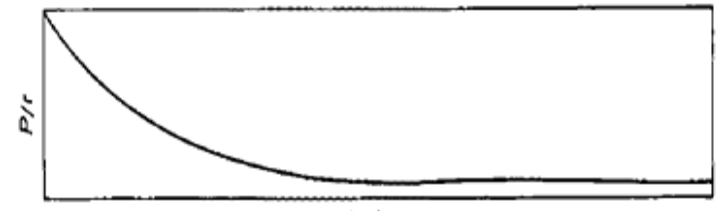

Angle 8 (radians)

Figure 3.The map of cortical reactivity observed by Cheer et al, 1987 where $P / r$ is the permeability of $\mathrm{Ca}^{2+}$ compartment/resequestration rate.
However this work describe simplicity the form the CSCR mechanism proposed by Cheer et al (1987) observed in certain fertilized amphibian eggs we present a calcium transient pattern in medaka egg surface. This phenomenon was reported years ago by some authors as Ridgway and Ashley (1967), Baker et al (1971), Fabiato and Fabiato (1975) and Endo et al (1970) that proposed the CSCR mechanism governed the excitation-contraction behavior of cardiac cells and skeletal muscle fibres. So to know the gradient of the transient $\mathrm{Ca}^{2+}$ concentration in the analyzed nerve, skeletal muscle fibres, cardiac cells or cortex of the amphibian eggs can be useful to understand the kinetic of in vivo release and reabsorption in these tissues.

\section{A simpler model for reaction diffusion system}

Cheer et al.(1987) described the kinetic of CSCR and resequestration as two processes: (a) The CSCR involves the release of calcium from membranous sequestering sites (CER) where the trigger of calcium release is a threshold concentration $c^{*}$ of calcium. So as reported by Murray (1989) this is a process whereby calcium, $\mathrm{Ca}^{2+}$, if perturbed above $c^{*}$, causes a dumping, of the sequestered calcium making the system to move to another steady state. This happens, from calcium sites on the membrane enclosing certain fertilized amphibian eggs as the medaka fish and (b) Resequestration calcium $\mathrm{Ca}^{2+}$ occurs also in such remain membrane. Without resequestration, the calcium level would in high level producing a wavefront which would advance over egg surface. So if we denoted the concentration of $\mathrm{Ca}^{2+}$ by $c$, the kinetics model can be naturally written as (Murray, 1989)

$$
f(c)=\hat{A}(c)-r(c)+L
$$

Where $\hat{A}(c)$ the autocatalytic release is rate of calcium, $r(c)$ its resequestration rate and $L$ represents a small leakage. As presented by Murray (1989) the specific form on the eq.(1) becomes

$$
\frac{d c}{d t}=L+\frac{k_{1} c^{2}}{k_{2}+c^{2}}-k_{3} c \quad(=f(c))
$$

where the $k^{\prime} s$ and $L$ are positive parameters. The qualitative form of $f(c)$ that would be used in our studies is illustrated in Fig.4 (Murray, 1989). 


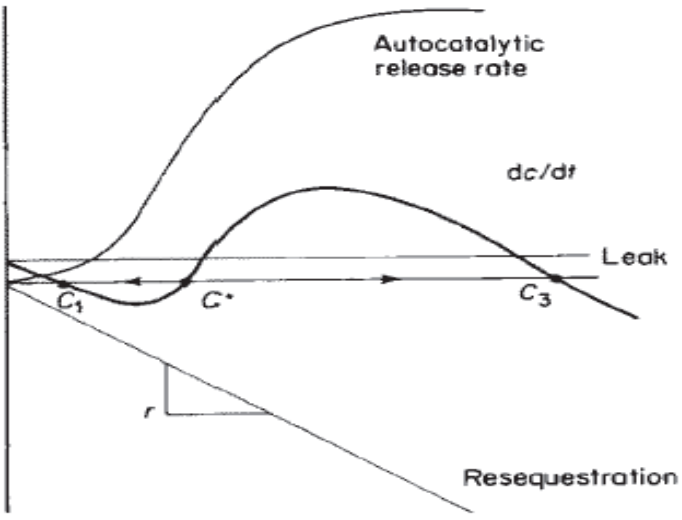

Figure 4. In this kinetic model $L$ is fixed and $f(c)$ has a qualitative dynamic behavior as a cubic polynomial with three positive zeros.

If supposed the calcium concentration on the surface of the egg is uniformly at the lower steady $c_{1}$ then the directions of the arrows in the Fig.4 indicate how $c$ will change when if a perturbation with a given concentration is introduced. If the perturbation is to a value less than $c_{2}=c^{*}, c \rightarrow c_{1}$ contrary $c \rightarrow c_{3}$ so $c_{2}$ is a threshold concentration. As reported by Murray (1989) the quantitative form in eq. (2) can only be seem a plausible caricature from the complexity of CSCR mechanism given by the eq. (1). Therefore, to make a simplifying caricature of eq.(2) preserving the qualitative dynamic behavior for the concentration $\mathrm{c}$ and the requisite three numbers of zeros is introduced a cubic namely presented by Murray (1989, fig.13.11b) namely

$$
\frac{d c}{d t}=f(c)=\tilde{A}\left(c-c_{1}\right)\left(c_{2}-c\right)\left(c-c_{3}\right)
$$

Where $\tilde{A}$ is a positive constant and $c_{1}<c_{2}<c_{3}$.

The simpler model for us adopted was related firstly by Murray (1989) is based on the CSCR process and that the $\mathrm{Ca}^{2+}$ diffuses happens on the cortex (surface) of the egg. Its mathematical description will involve only the polar angle $\theta$ measured from the top of the sphere and varying between zero and pi. The $\mathrm{Ca}^{2+}$ wavefront must increase its periphery in the northern hemisphere as it advances while decreasing with increasing latitude (See the last frame in Fig. 2) in agreement with the gradient of reactivity along the egg (given by the map of cortical reactivity obtained by Cheer et al., 1987, Fig. 3). We take the mathematical model reaction diffusion system presented by Murray (1989) to describe the CSCR process and the diffusion of calcium on the medaka egg surface as

$$
\frac{\partial c}{\partial t}=\tilde{A}\left(c-c_{1}\right)\left(c_{2}-c\right)\left(c-c_{3}\right)+D\left(\frac{1}{R}\right)^{2}\left(\frac{\partial^{2} c}{\partial \theta^{2}}+\frac{\partial c}{\partial \theta} \cot \theta\right)
$$

Where $D$ is a diffusion parameter and $R$ is the ratio of the egg.

\section{Methods}

The difference finite method was applied in the eq. (4) using the approximations

$$
\begin{gathered}
\frac{\partial^{2} c}{\partial \theta^{2}} \cong \frac{c_{i+1}^{n+1}-2 c_{i}^{n+1}+c_{i-1}^{n+1}}{\Delta \theta^{2}} \\
\frac{\partial c}{\partial \theta} \cong \frac{c_{i+1}^{n}-c_{i}^{n}}{\Delta \theta} \\
\frac{\partial c}{\partial t} \cong \frac{c_{i}^{n+1}-c_{i}^{n}}{\Delta \theta}
\end{gathered}
$$

Where $\theta_{i}=i \Delta \theta, \quad \theta i=0 . . N, t_{j}=j \Delta t, j=0 . . n$

Substituting eqs. (5-7) into eq. (4), resulte a TriDiagonal Matrix Algorithm (TDMA)

$$
A c_{i+1}^{n+1}+B c_{i}^{n+1}+C c_{i-1}^{n+1}=E c_{i}^{n}+F c_{i+1}^{n}+G
$$

Where $A=-D \Delta t, B=R^{2} \Delta \theta^{2}+2 D \Delta t, C=-D \Delta t$, $E=R^{2} \Delta \theta^{2}-D \Delta t \Delta \theta \cot \theta_{i}$,

$F=D \Delta t \Delta \theta \cot \theta_{i}$ and $G=R^{2} \Delta \theta^{2} \Delta t f\left(c_{i}^{n}\right)$.

For each fixed $j(j=0, . ., n-1)$ is associated a $N-1 \times N-1$ TDMA system where all concentrations $c_{i}^{j}$ can be estimated by iterative Gauss-Seidel method.

\section{Results and Discussion}

The boundary conditions for eq. (4) are:

$$
c(\theta, t=0)=0, \theta>0
$$

It is a natural condition, because we think that the entry of the sperm in mycropole in zero time must not make raises free calcium in other regions of the egg surface. This condition also was proposed by Cheer et al.(1987). They also proposed the second condition as $\left.\frac{\partial c}{\partial t}\right|_{\theta=0} ^{t=0}=0$, however no details was given by the authors for their choice.

As said later Ridgway et al.(1977) and Gilkey et al.(1978) observed that the calcium level in medaka eggs (using light emitting protein aequorin technique to follow changes in free calcium concentration during fertilization of eggs from medaka) when upon activation by sperm (or by ionosphere) presented a dramatic increase in the cytoplasmic calcium concentration returned to virtually resting levels, and finally, subsequent development proceeds with occasional small calcium transients. They also reported that the main rising phase of sperm-induced (or ionosphere- 
induced) calcium transients is exponential and the last phase has small calcium transients. So we assumed the original second condition to model the explosive raise of calcium in the animal pole $(\theta=0)$ using a Gompertz model presented by Boyce and DiPrima (1997) used to governing the increasing of population of certain species. The Gompertz model (eq. 10) was so used for us to simulate the concentration of $\mathrm{Ca}^{2+}$ in the cortex at the site of sperm entry and in the vegetal pole.

$$
\frac{d y}{d t}=r y \ln \frac{K}{y}
$$

Where the solution is

$$
y=K\left(\frac{y_{0}}{K}\right)^{\exp (-r t)}
$$

Where $K_{1}$ in our studies are the maximum concentration $c(0, t), t \geq 0$, and $c(\pi, t), t \geq 0$ and $y_{0}$ can be seem the initial concentration and $r$ are the rates of increasing. Differently of the strategy adopted by Lane et al. (1987) that modeled both the mechanical and mechanochemical waves observed in amphibian eggs with different model assumptions our objective was obtain a pattern from the concentration of calcium transient in surface of medaka egg. Some parameters used in our simulations can be considered as medium values obtained of the data reported by Gilkey et al.(1978) and Cheer et al.(1987) being the $r$ parameters taken as empirical values. The position of the $c_{i \prime s}$ also were taken in restricted locations (Gilkey et al., 1987), although could be taken in any region of the surface of the egg. The parameters used in our

\begin{tabular}{|c|c|c|}
\hline Dates & Notation & Value \\
\hline Radius of the egg & $R$ & $0.06 \mathrm{~cm}$ \\
\hline Diffusion coefficient & $D$ & $1.0 \times 10^{-5} \mathrm{~cm}^{2} \mathrm{~s}^{-1}$ \\
\hline $\begin{array}{ll}\text { Inverter } & \text { coefficient } \\
\text { amplitude } & \end{array}$ & $A$ & $9.0 \times 10^{-6} \mathrm{~cm}^{2} \mathrm{~s}^{-1}$ \\
\hline $\begin{array}{l}\text { Rate associated with } \\
\text { increased } \\
\text { concentration }\end{array}$ & $r$ & $0.081\left(s^{-1}\right)$ \\
\hline $\begin{array}{l}\text { Initial concentrations } \\
\text { of } \mathrm{Ca}^{2+}\end{array}$ & $\begin{array}{l}y_{01} \\
y_{02}\end{array}$ & $\begin{array}{l}1.58 \times 10^{-7} \text { molar } \\
9.9 \times 10^{-8}\end{array}$ \\
\hline $\begin{array}{lr}\text { Initial } & \text { concentrations } \\
\text { in } & \text { threshold } \\
\text { concentration in } \theta_{i}{ }^{*}\end{array}$ & $\begin{array}{l}c_{1} \\
c_{2} \\
c_{3}\end{array}$ & $\begin{array}{l}1.5 \times 10^{-7} \text { molar } \\
1.6 \times 10^{-7} \\
1.8 \times 10^{-7}\end{array}$ \\
\hline $\begin{array}{l}\text { Maximum } \\
\text { concentration of } \\
\text { calcium in the } \\
\text { beginning }\end{array}$ & $\begin{array}{l}K_{1} \\
K_{2}\end{array}$ & $\begin{array}{l}1.0 \times 10^{-6} \text { molar } \\
1.0 \times 10^{-7}\end{array}$ \\
\hline
\end{tabular}
studies in the model given by eq. (4) were: *where: $\theta_{1}=\frac{\pi}{2}, \theta_{2}=\frac{2 \pi}{3}$ and $\theta_{3}=\frac{5 \pi}{6}$

The empirical linear diffusion is defined as

$$
D(\theta)=1.0 \times 10^{-5}-1.4 \times 10^{-6} \theta
$$

Where $0<\theta<\pi$ with $D(\theta)$ decreasing slowly in relation of the fixed $D$ diffusion parameter.Fig.6 shows the pattern of the $\mathrm{Ca}^{2+}$ concentration along the egg with an expressive decreasing until the equator latitude and the $\mathrm{Ca}^{2+}$ concentration maintained constant after the equator. No significantly difference seems to be with the $D$ fixed and $D$ variable diffusion adopted parameters.

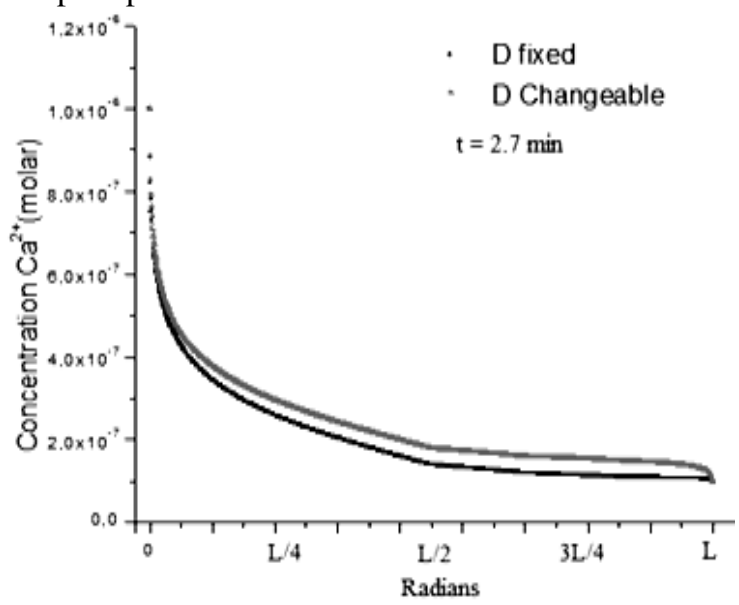

Figure 6. $\mathrm{Ca}^{2+}$ concentration pattern along the egg medaka fish surface with a D fixed and a changeable D .

There is an agreement with the map of the cortical reactivity (Fig.3) and the pattern of $\mathrm{Ca}^{2+}$ concentration along the egg medaka pattern showed in Fig.6. Our main resulted is that the $\mathrm{Ca}^{2+}$ concentration on the cortex of the egg must be higher before the equator latitude because the gradient of cortical chemical reactivity is highest in the animal hemisphere and tapering off towards the vegetal hemisphere. In other words as reported by Cheer et al.(1987) the animal hemisphere is more kinetically active than the vegetal hemisphere. Using a changeable $D$ diffusion parameter a small increasing of $\mathrm{Ca}^{2+}$ concentration was observed in surface of medaka egg when in comparison with the fixed $D$ diffusion parameter. Seems for us more realistic the model because to use a changeable $D$ diffusion parameter because the cortical proprieties are not uniform on the egg surface. Since as related by Yoshimoto et al (1986), that the propagation of the $\mathrm{Ca}^{2+}$ wave over the entire cortex of the egg is due to an active CSCR mechanism rather than to passive diffusion is suggested by us, not a proof, that the sensible variation of $\mathrm{Ca}^{2+}$ concentration in the region between 0 until $90^{\circ}$ (Fig. 6) can be attributed the kinetics of resequestration of $\mathrm{Ca}^{2+}$. The obtaining of realistic parameters for the eq. (4) must be very difficult and needs the experimental measures as example the 
resequestration rate parameter can be determined from measurements on the decrease in luminescence of aqueorin technique (Cheer et al.,1987).

\section{Conclusions}

We have adopted the simpler model only for the calcium concentration for the cortex of the egg medaka fish. No significantly changes were noted between the models one with a D fixed diffusion parameter and other com a variety $D$ diffusion parameter with a slowly constant rate of decreasing. Our main resulted is that the $\mathrm{Ca}^{2+}$ concentration pattern on the cortex of the egg was in agreement with the gradient of cortical chemical reactivity that is highest in the animal hemisphere and tapering off towards the vegetal hemisphere. And was suggested, not a proof that in animal hemisphere seems there is a stronger resequestration capacity of free calcium although the free calcium can be to passive diffusion into the interior of the egg medaka fish.

\section{References}

Boyce W.E. and DiPrima R.C. (2001). Equações Diferenciais Elementares e Problemas de Valores de Contorno, LTC Editora.

Cheer, A. Nuccitelli, R. Oster, G.F. and. Vincent J.P. (1987). Cortical activity in vertebrate eggs I: The activation waves. J. theor. Biol., 124, pp. 377-404. DOI: 10.1016/S0022-5193(87)80217-5

Dumollard, R. et al., (2002) Calcium wave pacemakers in eggs, Journal of Cell Science, The Company of Biologists Ltd. 115, pp. 3557-3564. DOI: $10.1242 /$ jcs.00056

Ferris, C. D, Snyder, S.H. (1992). IP3 receptors. Ligand-activated calcium channels in multiple forms. Adv Second Messenger Phosphoprotein Res., 26, pp. 95-107.

Gilkey, J. Jaffe, L. Ridgway, E. and Reynolds, G. (1978). A free calcium wave traverses the activating egg of the Medaka, Oryzias Latipes. J. C. The Journal of Cell Biology, 76, pp. 448466. 10.1083 /jcb.76.2.448

Jaffe, L.F. (1993). Classes and mechanisms of calcium waves. Cell Calcium. pp. 738-745. DOI: 10.1016/0143-4160(93)90099-R

Jaffe, L.F. (2008) . Calcium Waves Phil. Trans. R. Soc. B 363, pp. 1311-1316. DOI: 10.1098/rstb.2007.2249

Ridgway, E. B., Gilkey J.C and Jaffe, L. F. (1977). Free calcium increases explosively in activating medaka eggs. Proc. Nati. Acad. Sci. USA Vol. 74, No. 2, pp. 623-627. Cell Biology.
Howard Kutchai, C. (2005). Cellular Physiology. In: Berne RM, Levy MN, editors. Physiology.

Keener J. and Sneyd, J. (1991). Mathematical Physiology. Ed Springer.

Lane, D.C., Murray, J.D. and Manoranjan, V.S. (1987). Analysis of wave phenomena in a morphogenetic mechanochemical model and an application to post-fertilization waves on eggs. IMA J. Math. Applied in Medic. and. Biol., 4, pp. 309-331. DOI: 10.1093/imammb/4.4.309

Murray, J. D. (1989). Mathematical Biology. Second Edition. Ed. Springer. New York, NY, USA.

Somlyo, A.P. and Somlyo, A.V. (1994). Signal transduction and regulation in smooth muscle. Nature Publishing Group, 372, pp. 231--236. DOI: $10.1038 / 372231 \mathrm{a} 0$

http://bioll.bio.nagoyau.ac.jp:8000/IwamatsuT92.html. Accessed in $01 / 2012$.

Yoshimoto, Y. et al. (1986). The Wave Pattern of Free Calcium Release Upon Fertilization in Medaka and Sand Dollar Eggs. Develop. Growth and Differ., 28 (6), pp.583-596. DOI: 10.1111/j.1440-169X.1986.00583.x

\section{Contribution of these paper}

Was used the Gompertz Model to "govern" the initial and final $\mathrm{Ca}^{2+}$ concentration in the surface of the medaka egg fish.

These concentrations were incorporate in the simplify transient model to the describe the $\mathrm{Ca}^{2+}$ concentration in the cortex upon fertilization in medaka egg fish. The results of the numeric simulation showed a reasonable agreement between the $\mathrm{Ca}^{2+}$ concentration pattern and the map of cortical reactivity observed by Cheer (1987) and other authors. 